\title{
Second year and running strong
}

\author{
Otis N. Crandell \\ Babeș-Bolyai University, Geology Department, Cluj-Napoca, Romania. Email: otis.crandell@gmail.com
}

Welcome to another issue of the Journal of Lithic Studies. This issue in fact marks our second year of publishing. We are definitely pleased with the progress that we have made so far and some of the new ideas that we have tried out.

One of our objectives in establishing JLS has been to introduce new ideas of how academic material can be published. Not only have we been encouraging researchers from a variety of countries and regions to submit their research to this journal, but we are also trying out different ideas to see how best we can disseminate research, findings, and other news.

This year we have started to publish in additional languages. A general topic issue, guest edited by Xavier Mangado, will be published in Spanish later this year. In connection with our publishing in Spanish, we have updated the journal's web site interface which is now available in both English and Spanish. Yan Axel Gómez Coutouly is guest editing a French language special topic issue on chaîne opératoire which we expect to come out in the middle of next year.

As well, we have started to other publish special topic issues. In addition to the chaîne opératoire issue currently in production, we are planning several other special issues, which are currently scheduled throughout 2016.

This has been a good year for collaborations with symposia, meetings and other academic events. We will be publishing the proceedings of several UISPP and EAA sessions from 2014 as well as independent symposia from 2015 as either special topic issues or issues dedicated to those events. The previously mentioned special topic issue on standing stones and megaliths is comprised of articles from presenters at the 2014 UISPP session "Standing stones and megalithic monuments in context”. Also from the 2014 UISPP is a special theme issue based on presentations from the session "Beyond the reduction sequence: new insights in lithic technology" which is being guest edited by Sara Cura. We have agreed to publish the proceedings of the "Ground Stone \& Society" international workshop (Haifa, July 2015), organised by the Association for Ground Stone Research (http://agsr2015.haifa.ac.il/). Danny Rosenberg will be guest editing this special topic issue. Not least of all, we are again collaborating with the organisers of the International Symposium on Knappable Materials (http://www.ub.edu/cherts-symp2015/), hosted by the University of Barcelona in September this year. This issue holds particular interest for us since the first issue of JLS was also dedicated to the proceedings of the previous symposium in this series. We are also discussing collaborations with other scientific event organisers about publishing their proceedings. We are very happy to lend our support to any lithics related event.

Published by the School of History, Classics and Archaeology, University of Edinburgh ISSN: 2055-0472. URL: http://journals.ed.ac.uk/lithicstudies/

This work is licensed under a Creative Commons Attribution 2.5 UK: Scotland License. 
Over the last year we have also been working hard to increase circulation and recognition of the journal by getting it included in international databases and indexes. Among these, some of the more well-known include DOAJ (the Directory of Open Access Journals) (https://doaj.org/toc/2055-0472), ERIH PLUS (the European Reference Index for the Humanities and the Social Sciences) (https://dbh.nsd.uib.no/publiseringskanaler/erihplus/periodical/info?id=486045), and recently Thomson Reuters Web of Science ESCI (Emerging Sources Citation Index).

We have published the six month and twelve month download and view reports for articles in the 2014 issues. We intend to continue doing this so that the status of our articles can be publicly evaluated and to keep our journal as transparent as possible. We feel that it is important for potential authors to be able to evaluate how much (or how little) coverage their articles would likely get if they publish in JLS. Very few journals do this but we hope that this policy will catch on throughout the academic publishing industry.

We have done very well in these first two years. We have moved forward a great deal. Hopefully we will carry on with the momentum and continue to develop and try out new ideas. In this way we also hope to attract the interest of an even larger audience. We are always interested in new ideas on how to improve academic publishing - how to make it more accessible, how to make it more appealing to more people, how to attract more readers. We look forward to another year of success in 2016.

Otis Crandell

Editor-in-Chief Journal of Lithic Studies 